\title{
UM ESTUDO SOBRE AS MANIFESTAÇÕES PATOLÓGICAS DAS CONSTRUÇÕES EM CONDOMÍNIOS DE PRÉDIOS RESIDENCIAIS NA REGIÃO METROPOLITÂNA DA GRANDE VITÓRIA-ES
}

\author{
VERONEZ, MARCELO \\ Engenheiro Civil, MSc. \\ Consultor Especialista em Eng ${ }^{\mathrm{a}}$ de Patologia das Construções \\ Espírito Santo; Brasil \\ mveronez@hotmail.com
}

\section{RESUMO}

Este trabalho apresenta um estudo do histórico das patologias das construções apontadas em 17 laudos de inspeção predial realizados em condomínios de prédios residenciais na região metropolitana de Vitória/ES. As inspeções prediais, realizadas nos últimos 10 anos, avaliaram as áreas comuns de prédios com idades entre 6 meses e 22 anos de entregues, e apontaram em média, 32 manifestações patológicas, 47 não conformidades com as normas técnicas da ABNT, e 38 não atendimentos à boa prática de engenharia, num total de 117 apontamentos. Ao final, observou-se que a maior parte das manifestações patológicas encontradas nas edificações estudadas, percentual superior a $80 \%$, se concentrou entre os itens de Projeto, de Especificação Técnica, e de Execução de Instalações Hidrossanitárias, de Paredes em Alvenaria, e de Impermeabilização; e um item importante observado no estudo foi que as construções mais novas foram aquelas que apresentaram a maior quantidade de apontamentos por laudo técnico.

Palavras-chave: falhas, laudo técnico, patologia das construções.

\section{ABSTRACT}

This paper presents a study of the pathologies identified in 17 building inspection reports carried out in condominiums of residential buildings in the metropolitan region of Vitória/ES. The building inspections, carried out in the last 10 years, evaluated the common areas of buildings aged between 6 months and 22 years of delivery, and indicated, on average, 32 pathological manifestations, 47 non-compliance with ABNT technical standards, and 38 non-attendance to good engineering practice in a total of 117 notes. In the end, it was observed that most of the pathological manifestations found in the studied buildings, higher than $80 \%$, were concentrated among the Design, Technical Specification, and Execution of Hydro Sanitary Installations, Masonry Walls, and Waterproofing; and an important item observed in the study was that the newer constructions were those that presented the highest number of notes by technical report.

Keywords: failures, technical report, building pathology.

\section{INTRODUÇÃO}

A Inspeção Predial é uma ferramenta que tem o propósito de avaliar o estado atual de conformidade de uma edificação, analisando diversos aspectos, como os de desempenho, de vida útil, de segurança, o estado de conservação da edificação, o cumprimento das manutenções preventivas, a exposição ambiental, a forma de utilização e de operação, observando as expectativas atuais dos seus proprietários (IBAPE, 2005).

O profissional de engenharia busca durante a Inspeção Predial detectar, numa primeira etapa, as anomalias e falhas nos elementos do imóvel e classificá-las de acordo com uma escala de grau de urgência e de risco. Uma vez mapeados todos estes elementos, ele deve apresentar um plano de correção, um plano de manutenção, e os serviços que devem ser realizados para a reabilitação das anomaliaa e das falhas observadas. O plano de correção deve ser executado por uma empresa de construção especializada para garantir a manutenção correta e o conserto daqueles sistemas que não estavam funcionando satisfatoriamente, segundo a concordância dos proprietários (IBAPE, 2009). 
Em um segundo momento da Inspeão Predial, também devem ser apontados os não-atendimentos aos requisitos das normas técnicas da ABNT - Associação Brasileira de Normas Técnicas, do Corpo de Bombeiros local, da Prefeitura, e outros padrões e normas que sejam cabíveis. E ainda, em um terceiro momento, o atendimento às boas práticas da construção (LICHTENSTEIN, 1985; VERÇOZA, 1991).

$\mathrm{Na}$ avaliação das manifestações patológicas, em consenso entre técnicos e proprietários, especial atenção deve dada aos probemas que podem ser encontrados nas estruturas. O primeiro motivo para esta atenção especial, vem da possibilidade de acontecimento de falhas catastróficas, e o segundo motivo vem do aumento de custo considerável para o reparo de uma falha estrutural, com o passar do tempo, por exemplo, quando as armaduras já foram comprometidas pela corrosão (CÁNOVAS, 1998; HELENE, 1992).

Verçosa (1991) destaca a responsabilidade dos profissionais de engenharia desde a etapa de projeto até a execução de uma edificação, e comenta que o conhecimento das patologias, em maior ou menor grau, para todos que trabalham na atividade de construção civil é de suma importância, pois quando se conhecem os defeitos que uma edificação pode apresentar, e as suas causas, é menos provável que se cometam os mesmos erros em situações idênticas. Este trabalho sumariza dados do trabalho de Inspeção Predial realizados pelo autor nos últimos 10 anos com esta intenção.

\section{METODOLOGIA}

Nesta seção estão apresentadas as metodologias de realização das Inspeções Prediais e da apresentação dos dados constantes dos laudos entregues aos proprietários.

\subsection{Realização das inspeções}

Segundo o IBAPE (2009), a Inspeção Predial é uma vistoria da edificação para avaliar suas condições técnicas, funcionais e de conservação, e o critério utilizado para elaboração da Inspeção baseia-se na análise do risco mediante o uso e a exposição ambiental. Neste contexto, a análise do risco consiste na classificação das anomalias ou falhas detectadas nos diversos componentes de uma edificação, quanto ao grau de urgência, relacionado com fatores de conservação, depreciação, saúde, segurança, funcionalidade e dos sistemas da edificação.

As Inspeções Prediais, ainda segundo o IBAPE (2009), são classificadas de acordo com o nível de complexidade pretendido pelo inspetor que, geralmente, é função da finalidade da inspeção, e os níveis de complexidade podem ser:

- Inspeção Predial de Nível 1 - realizada com uma vistoria para a identificação das anomalias aparentes, elaboradas por um profissional habilitado;

- Inspeção Predial de Nível 2 - realizada com uma vistoria para identificação de anomalias aparentes identificadas com o auxílio de equipamentos, elaborada por profissionais de diversas especialidades; e

- Inspeção Predial de Nível 3 - realizada com uma vistoria para identificação de anomalias aparentes e ocultas constatáveis com o auxílio de equipamentos, incluindo testes e ensaios locais e/ou laboratoriais específicos, elaborada por profissionais de diversas especialidades.

Em todas as Inspeções Prediais apresentadas neste trabalho foi adotado pelo inspetor o Nível 2 de complexidade, sendo realizadas vistorias para identificação de anomalias aparentes, e a identificação com o auxílio de equipamentos.

A classificação da Qualidade de Manutenção, por sua vez, considera as falhas constatadas na edificação, as rotinas e a execução das atividades de manutenção e as taxas de sucesso, dentre outros aspectos. Nessa avaliação:

- A Qualidade da Manutenção Atende - quando o sistema ou o elemento fonte de manutenção está em pleno funcionamento, desempenhando a sua função plenamente;

- A Qualidade da Manutenção Atende Parcialmente - quando o sistema funciona, porém com falha no seu desempenho; ou

- A Qualidade da Manutenção Não Atende - quando o sistema não desempenha mais a função esperada. 
Para a classificação do uso da edificação, observam-se as condições originais e os seus sistemas construtivos, além dos limites de utilização e suas formas, e assim o uso da edificação pode ser classificado em:

- Uso Regular - quando a edificação é utilizada segundo a concepção original e seguindo aos limites e formas de utilização dos seus sistemas construtivos; ou

- Uso Irregular - quando a edificação não é utilizada segundo a concepção original e seguindo aos limites e formas de utilização dos seus sistemas construtivos.

Ainda segundo o IBAPE (2009), as anomalias encontradas por ocasião da Inspeção Predial são classificadas quanto ao seu Grau de Urgência, sendo eles:

- Grau de Urgência Crítico - quando a anomalia apresenta risco iminente contra a saúde e segurança;

- Grau de Urgência Regular - quando a anomalia apresenta risco à funcionalidade; e

- Grau de Urgência Mínimo - quando a anomalia apresenta risco de desvalorização precoce.

Em todas as Inspeções Prediais apresentadas neste trabalho o avaliador apontou o Grau de Urgência para cada uma das anomalias, sejam manifestações patológicas, não conformidades com as normas técnicas da ABNT, ou não atendimentos à boa prática de engenharia.

As Inspeções Prediais, ao final, têm o propósito de classificar também a edificação quanto ao seu estado de conservação, segundo o IBAPE (2009), podendo ela estar enquadrada em:

- Estado de Conservação Crítico - quando a edificação possui anomalias classificadas com Grau de Urgência Crítico, ou seja, sem condições de uso;

- Estado de Conservação Regular - quando a edificação contém anomalias classificadas com Grau de Urgência Regular, ou seja, sujeito a reparos; ou

- Estado de Conservação Satisfatório - quando a edificação não contém anomalias significativas, estando ela em situação normal.

Em todas as Inspeções Prediais apresentadas neste trabalho as edificações foram classificadas quanto ao Estado de Conservação, seguindo os critérios do IBAPE (2005;2009).

As Inspeções Prediais deste trabalho foram realizadas em prédios de apartamentos residenciais entre 6 e 16 pavimentos, por solicitação expressa do responsável pela edificação, via de regra, o Síndico do Condomínio. Nestas ocasiões, as solicitações já vieram com informações iniciais de que havia manifestações patológicas de Grau de Urgência Crítico, especialmente por envolver elementos estruturais. Esta informação é importante, pois o universo de anomalias estudado faz parte daquele onde as edificações já possuem histórico crônico de manifestações patológicas, ou seja, em princípio não constam neste trabalho edificações bem projetadas, bem excutadas e bem manutenidas e utilizadas, segundo o que se entende por Lichtenstein (1985) e Verçoza (1991).

Para cada registro de anomalia encontrado nas inspeções, um perfil foi descrito utilizando um check-list previamente elaborado pelo autor. Os principais itens deste check-list são:

1. O elemento no qual se observou a anomalia foi construido assim como projetado? Observando projetos, desenhos, especificações, etc;

2. O projeto/especificação do elemento no qual se observou a anomalia era adequado? Observando detalhes construtivos, compatibilidade entre materiais, solicitações de esforços mecânicos, etc;

3. O elemento no qual se observou a anomalia tinha o seu uso descrito no Manual do Proprietário? Observando se estavam especificados os limites de utilização para o elemento; 
4. Os usuários conheciam o uso do elemento no qual se observou a anomalia, assim como estava descrito no Manual do Proprietário?

5. O elemento no qual se observou a anomalia tinha a sua manutenção preventiva ou preditiva descrita no Manual do Proprietário?

6. Os funcionários/responsáveis conheciam a manutenção do elemento no qual se observou a anomalia, assim como estava descrito no Manual do Proprietário?

7. O elemento no qual se observou a anomalia ou falha já havia passado por outra inspeção predial antes da realização da atual?

8. O elemento no qual se observou a anomalia já havia passado por manutenção corretiva (por pelo menos 1 vez) antes da atual inspeção?

9. O elemento no qual se observou a anomalia, na percepção do usuário/responsável, continua em avanço no processo de degradação?

10. O elemento no qual se observou a anomalia, na percepção do usuário/responsável, corresponde a uma ocorrência "crítica"? Considerada como "crítica" aquela anomalia que demanda uma manutenção corretiva imediata.

As respostas para as perguntas acima - registradas nos check-lists, após subsidiarem a confecção do laudo da inspeção, foram catalogadas e mantidas para utilização posterior.

É importante observar que algumas destas questões levantadas no check-list não foram atendidas por algumas das edificações por inobservância ou improcedência do questionamento, como por exemplo, nas edificações mais antigas, que não foram construidas em uma realidade da construção civil que se mantinha um Manual do Proprietário com todas as recomendações avaliadas.

\section{APRESENTAÇÃO DOS RESULTADOS}

Nesta seção estão apresentadas as compilações dos resultados da avaliação das anomalias ou falhas nas 17 edificações residenciais (prédios de apartamentos), levadas em consideração as perguntas respondidas no check-list, apresentadas na seção anterior.

É importante frisar que os dados deste trabalho se tratam de resultados de inspeções onde já se sabia de antemão que havia anomalias e falhas nas edificações, por solicitação expressa dos proprietários, não sendo neste sentido um estudo que contemple aleatoriedade e, logo, rigor nas indicações dos resultados.

Num primeiro instante, estão apresentadas, caso a caso, as anomalias constantes dos questionamentos que foram apresentados no item anterior, isoladamente uma da outra, para se ter uma condição de avaliar a frequência que acontecem cada tipo de anomalia, mesmo que não sejam a ocorrência que preponderou como causa da anomalia. Isto, por que pode ter ocorrido mais de uma anomalia em um mesmo elemento, não sendo uma delas a responsável pelo mau funcionamento ou falha do elemento.

Mais adiante estão apresentadas a relação contendo todas as ocorrências em conjunto, avaliando-se qual foi a causa principal da anomalia segundo o que foi entendido pelo inspetor naquela ocasião de confecção do laudo de Inspeção Predial.

A Tabela 1 - apresentada a seguir, mostra a relação de ambientes avaliados nas Inspeções Prediais estudadas neste trabalho, nas quais foram apontados anomalias ou falhas. Pode-se observar a grande diversidade de ambientes, sendo possível identificar praticamente todos os compartimentos que podem fazer parte de uma edificação típica daquelas que foram estudadas - prédios residenciais entre 6 e 16 pavimentos. 
Tabela 1 - Lista de ambientes avaliados nas inspeções prediais estudadas

\begin{tabular}{|c|c|c|c|}
\hline \multicolumn{4}{|c|}{ Ambientes Avaliados } \\
\hline Setor & Ambiente/local & Setor & Ambiente/local \\
\hline \multirow{9}{*}{ Serviço } & Loja & \multirow{14}{*}{ Telhado/cobertura } & Laje sem impermeabilização \\
\hline & Lavanderia & & Laje impermeabilizada \\
\hline & Academia & & Laje em pavimento de serviço \\
\hline & Cozinha & & Telhado em madeira \\
\hline & Banheiro & & Platibanda revestida com cerâmica \\
\hline & Vestiário & & Platibanda revestida com pintura \\
\hline & Oficina & & Platibanda em concreto aparente \\
\hline & Almoxarifado & & Rufos em concreto \\
\hline & Laje de serviço (ar condicionado) & & Rufos em metal \\
\hline \multirow{12}{*}{ Lazer } & Churrasqueira & & Calhas em concreto \\
\hline & Piscina & & Calhas em alvenaria \\
\hline & Cozinha de A.L. & & Calhas em metal \\
\hline & Playground & & Laje técnica (de antenas) \\
\hline & Quadra revestida em cimentado & & Dispositivos para andaime externo \\
\hline & Quadra revestida em borracha & \multirow{8}{*}{ Jardim e afins } & Jardineiras em lajes \\
\hline & Quadra revestida em madeira & & Jardineiras em fachada \\
\hline & Quadra revestida em grama sintética & & Jardineiras em pisos \\
\hline & Sauna & & Jardim seco \\
\hline & Área de repouso (área molhada) & & Jardim molhado \\
\hline & Área de repouso (área seca) & & Horta em área aberta (descoberta) \\
\hline & Salão de festas & & Horta em área fechada (coberta) \\
\hline \multirow{13}{*}{ Garagem } & Garagem em subsolo & & Gramado natural \\
\hline & Garagem em ambiente aberto & \multirow{28}{*}{ Dependências } & Fosso de elevador \\
\hline & Garagem em pavimento elevado & & Casa de máquinas de elevador \\
\hline & Rampa de acesso de automóveis & & Vão de elevador \\
\hline & Rampa de elevação de automóveis & & Área de correspondências (armários) \\
\hline & Portão automático de automóveis & & Sala de estar \\
\hline & Portão manual de automóveis & & Banheiro de visitantes \\
\hline & Área de manobra & & Banheiro de serviço \\
\hline & Pista de acesso & & Banheiro de portaria \\
\hline & Área de lava-jato & & Almoxarifado (materiais) \\
\hline & Oficina/manutenção & & Sala de segregação de lixo \\
\hline & Depósito & & Lixeiras \\
\hline & Armários de Garagem/Boxes & & Elevador de serviço \\
\hline \multirow{16}{*}{ Dependências } & Hall de entrada & & Elevador social \\
\hline & Hall de elevador & & Elevador de acessibilidade \\
\hline & Sala da portaria & & Elevador de automóveis \\
\hline & Escritório de Síndico & & Escada em madeira/decorativa \\
\hline & Bicicletário & & Recepção de serviço \\
\hline & Refeitório & & Recepção social \\
\hline & Cozinha & & Sala de estar/recepção \\
\hline & Escada de saída de emergência & & Área de ventilação (natural) \\
\hline & Escada de acesso & & Área de ventilação (forçada) \\
\hline & Calçada externa & & Sala de dutos de ar condicionado \\
\hline & Calçaca interna & & Sala de estudos \\
\hline & Rampa de acesso de pedestre & & Almoxarifado (ferramentas) \\
\hline & Portão automático de pedestre & & Área de serviço (molhada) \\
\hline & Portão manual de pedestre & & Área de serviço (seca) \\
\hline & Sala de repouso (interna) & & Sala de medidores \\
\hline & Sala de repouso (externa) & & Outros \\
\hline
\end{tabular}




\subsection{Frequência e características das anomalias}

Nos laudos estudados, os apontamentos foram realizados classificando cada item em (1) manifestação patológica, (2) não conformidade com as Normas da ABNT, ou (3) não atendimento à boa prática. A Tabela 2, a seguir, apresenta os apontamentos dos 17 laudos estudados. Nela, pode-se observar que, em média, foram apontados 32 manifestações patológicas, 47 não conformidades, e 38 não atendimentos à boa prática de engenharia, em cada avaliação de imóvel.

Tabela 2 - Lista detalhada de apontamentos nos laudos estudados

\begin{tabular}{c|c|c|c|c|c}
\hline Laudo & Idade & Total de anomalias & Manifestações patológicas & Não conformidades & NA à boa prática \\
\hline Imóvel 1 & 0,5 & 142 & 52 & 67 & 23 \\
\hline Imóvel 2 & 3 & 138 & 61 & 71 & 6 \\
\hline Imóvel 3 & 3 & 152 & 54 & 61 & 37 \\
\hline Imóvel 4 & 5 & 187 & 58 & 59 & 70 \\
\hline Imóvel 5 & 5,5 & 102 & 32 & 40 & 30 \\
\hline Imóvel 6 & 7 & 94 & 30 & 40 & 24 \\
\hline Imóvel 7 & 7 & 133 & 27 & 58 & 48 \\
\hline Imóvel 8 & 8,5 & 97 & 19 & 49 & 29 \\
\hline Imóvel 9 & 8,5 & 115 & 22 & 62 & 31 \\
\hline Imóvel 10 & 8,5 & 108 & 17 & 25 & 46 \\
\hline Imóvel 11 & 9,5 & 68 & 12 & 27 & 34 \\
\hline Imóvel 12 & 9,5 & 72 & 22 & 71 & 23 \\
\hline Imóvel 13 & 11 & 131 & 30 & 38 & 30 \\
\hline Imóvel 14 & 16 & 112 & 20 & 40 & 18 \\
\hline Imóvel 15 & 17 & 84 & 26 & 25 & 78 \\
\hline Imóvel 16 & 22 & 135 & 32 & 32 & 51 \\
\hline Imóvel 17 & 22 & 120 & 37 & 47 & 38 \\
\hline MÉDIA & 10 & 117 & 32 & & \\
\hline
\end{tabular}

Analisando os dados da Tabela 2 pode-se observar que, se avaliados apenas os imóveis mais novos (entre 0,5 e 5,5 anos), a média de apontamento é de 144 anomalias, sendo 51 manifestações patológicas, 59 não conformidades com as normas da ABNT, e 34 não atendimentos à boa prática. Estes dados estão melhor observados na Figura 1.

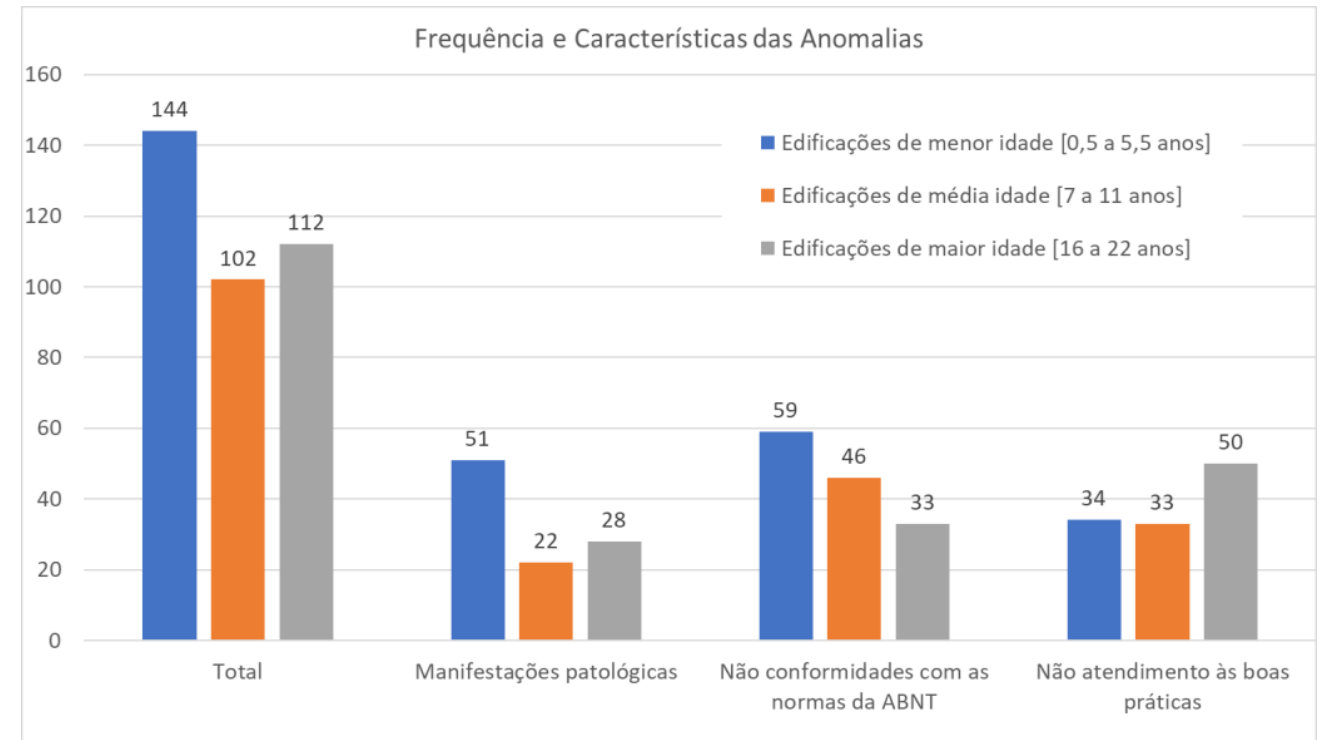

Figura 1: Frequência e características das anomalias estudadas neste trabalho

Considerando agora, respectivamente, os imóveis entre 7 e 11 anos (de média idade) e os imóveis entre 16 e 22 anos (de maior idade), como pode ser percebido na Figura 1, as manifestações patológicas, em média, foram de 22 e de 28 apontamentos, com média de 102 e 112 apontamentos totais de anomalias em cada laudo.

Pela avaliação da Figura 1, pode-se concluir que os imóveis mais novos mostraram um tendência de apresentar mais anomalias que os imóveis mais antigos. 


\subsection{Obediência aos requisitos de projeto}

Na Figura 2 estão apresentados os números do atendimento ao que foi projetado para a edificação, nos casos das manifestações patológicas, das não conformidades com as normas da ABNT, e do não atendimento às boas práticas da construção. Assim, por exemplo, em 65\% dos elementos avaliados e descritos na Tabela 2 foi obervado o atendimento às suas especificações de projeto, e em $35 \%$ deles as especificações e características de projeto não foram atendidas. Observa-se na figura que houve predominância das manifestações patológicas naqueles elementos que não observaram o que foi projetado/especificado (58\%) para a sua construção.

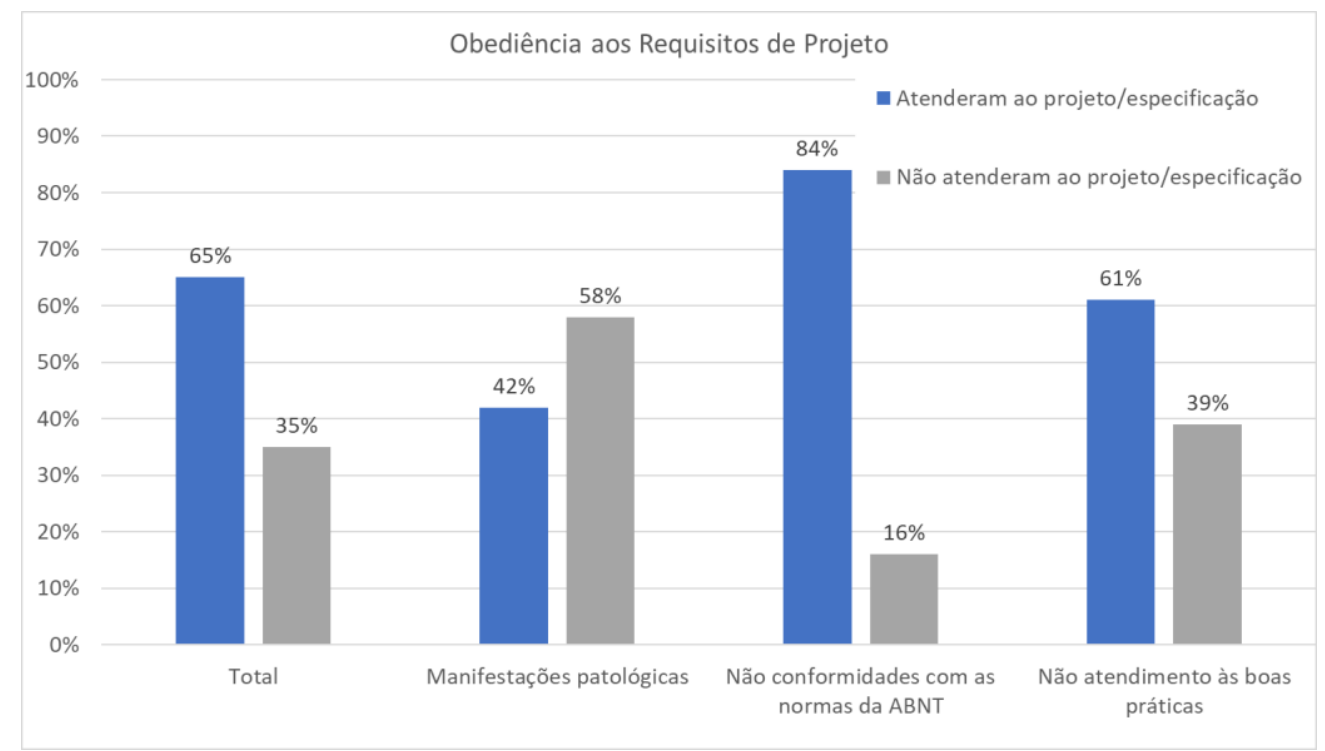

Figura 2: Obediência aos requisitos de projeto das anomalias estudadas neste trabalho

É importante observar na Figura 2 que a maior parte das não conformidades com as normas da ABNT - 84\%, e dos não atendimentos às boas práticas da construção - $61 \%$, se deu em elementos que foram construídos e manutenidos de acordo com o projeto/especificação.

\subsection{Adequação do projeto/especificação}

A Figura 3, a seguir, apresenta a avaliação da adequação do projeto/especificação das anomalias estudadas neste trabalho e apresentadas na Tabela 2, e percebe-se a carência de atendimento dos projetos/especificações às normas da ABNT $(91 \%)$ e às boas práticas $(75 \%)$.

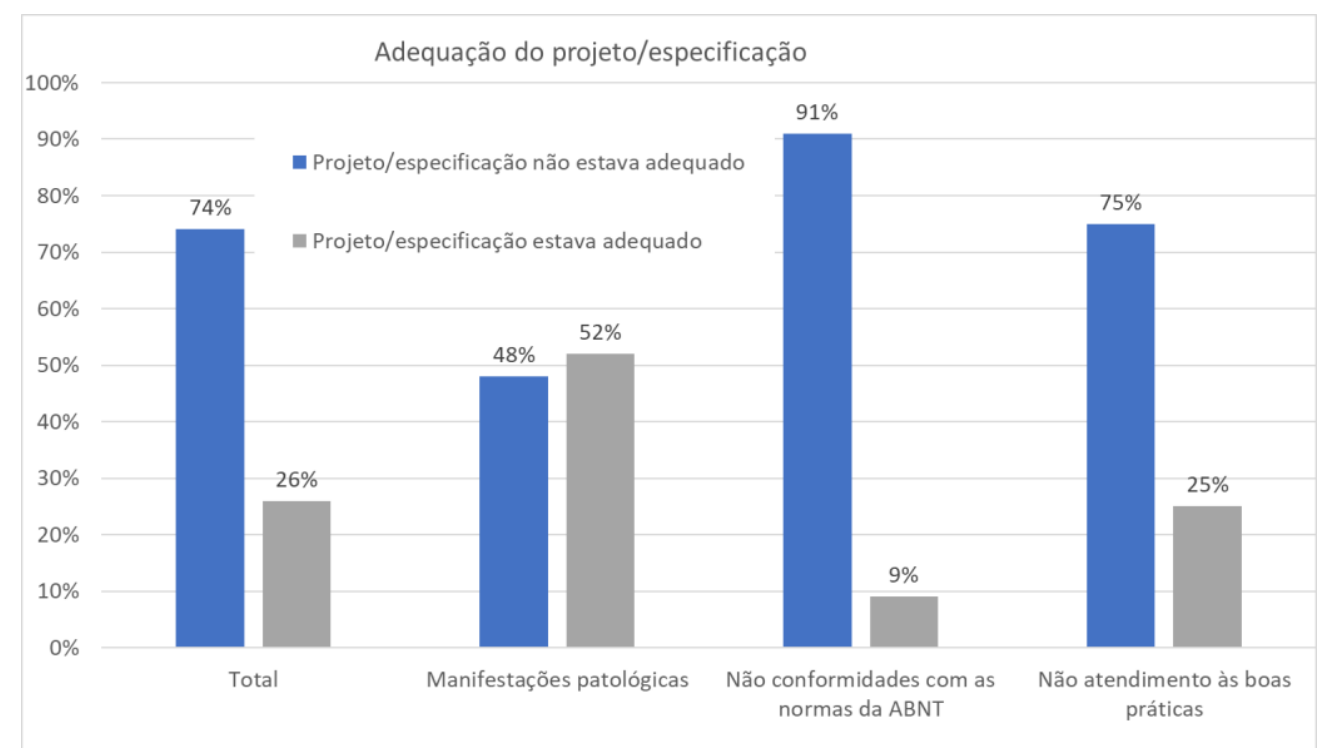

Figura 3: Adequação do projeto/especificação das anomalias estudadas neste trabalho 
É importante ressaltar que as avaliações de não conformidade e de não atendimento às boas práticas, apresentadas na Figura 3, levaram em consideração os requisitos técnicos atuais, e não aqueles praticados à época do projeto, o que quer dizer que não necessáriamente os elementos avaliados foram mal projetados, apenas eles estão fora dos requisitos atualmente adotados como boa técnica e boa prática da construção.

\subsection{Adequação do uso}

O Uso adequado dos elementos estudados está apresentado na Figura 4. Nela pode-se observar que em 59\% das anomalias estudadas o uso do elemento estava descrito no Manual do Proprietário, e em 65\% dos casos o usuário possuia o conhecimento do uso correto do elemento, embora em alguns destes casos as informações não constassem no Manual do Proprietário e o usuário obtinha as informações por meios não específicos para aqueles elementos.

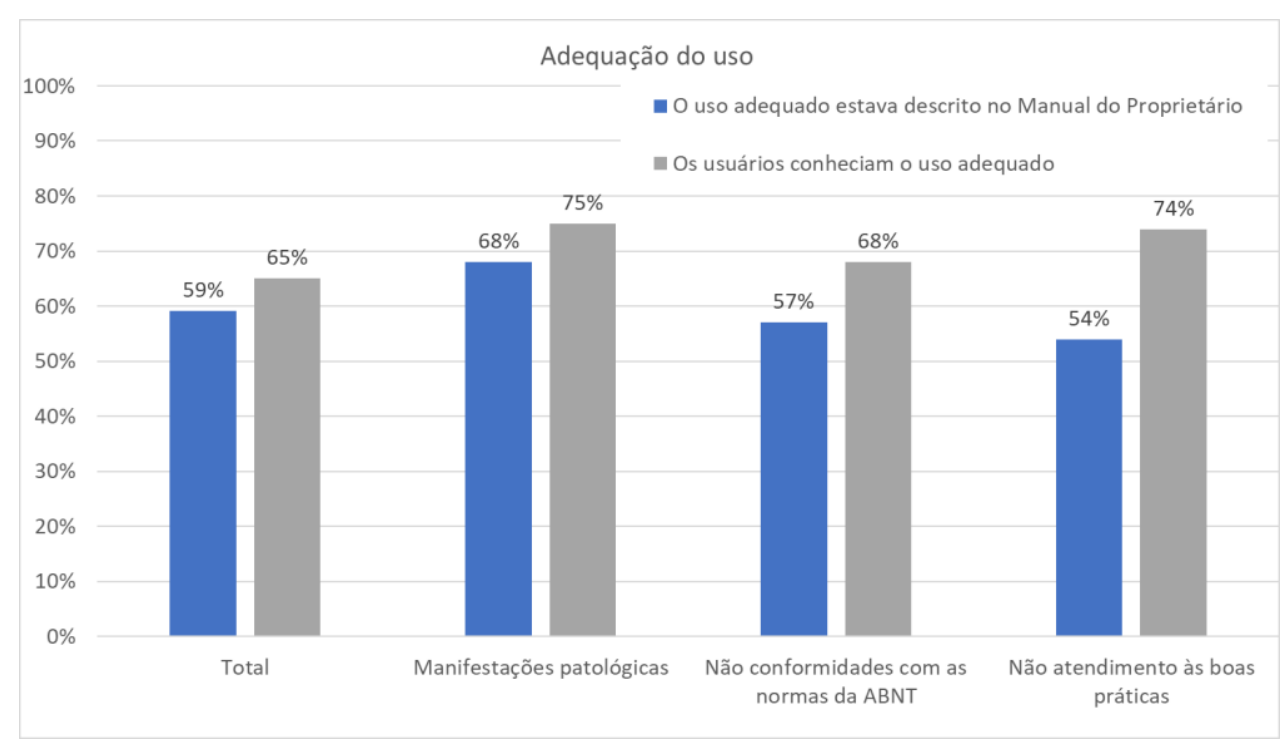

Figura 4: Adequação do uso das anomalias estudadas neste trabalho

O reduzido número de descrições de uso no Manual do Proprietário (59\%) também deveu-se àquelas edificações que não possuiam este documento, especialmente devido a não se tratar de uma prática da construção na oportunidade de projeto e construção da edificação.

\subsection{Adequação da manutenção}

A Figura 5 apresenta a avaliação da manutenção. Percebe-se nela a carência de atendimento deste item nos Manuais de Proprietário. A avaliação do conhecimento foi relativa aos casos em que a informação constava no Manual.

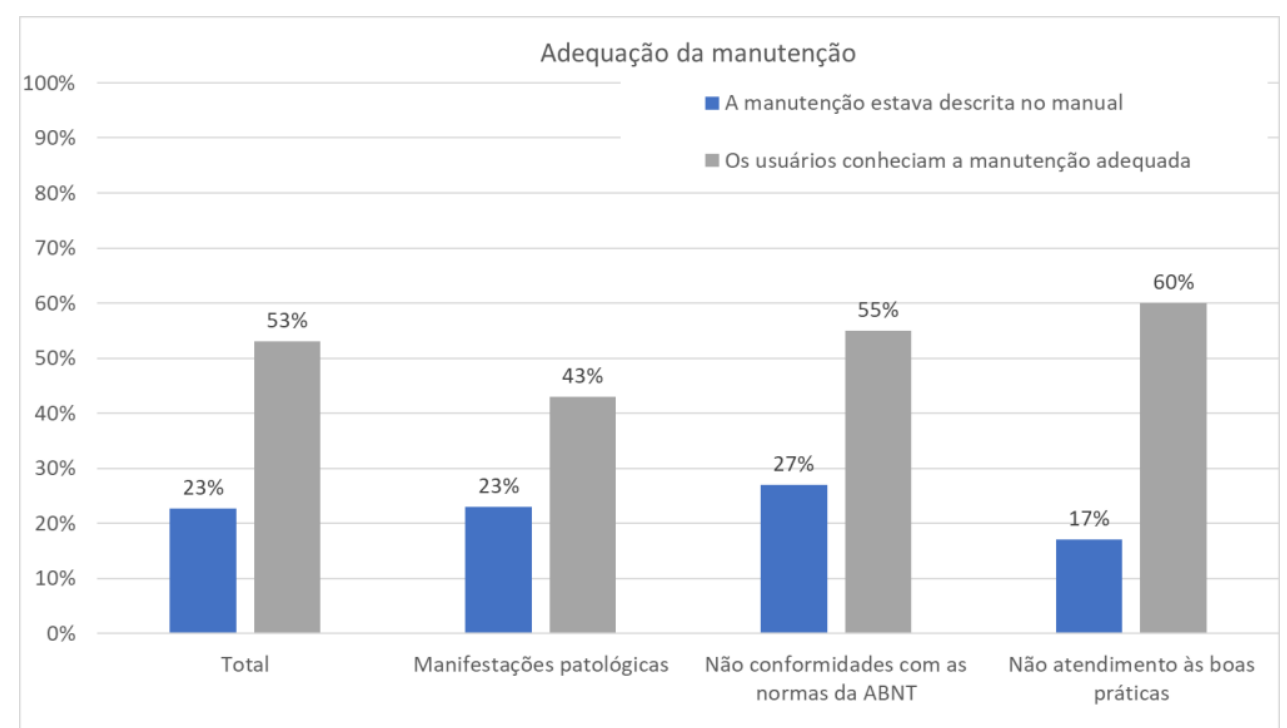

Figura 5: Adequação da manutenção das anomalias estudadas neste trabalho 


\subsection{Avaliação dos antecedentes}

Na Figura 7 estão apresentados os números da avaliação dos antecedentes dos elementos nos quais foram observadas as anomalias, descritas na Tabela 2, observando-se que $9 \%$ deles já havia passado por algum tipo de manutenção corretiva ou por algum tipo de adequação e que $13 \%$ deles já havia passado por alguma inspeção técnica anteriormente. A frequencia desta avaliação foi observada também nas manifestações patológicas, em maior escala (com 16 e $20 \%$, respectivamente) e nos não atendimentos às boas práticas (com 12 e 18\%, respectivamente), e em menor escala nas não conformidades com as normas da ABNT, com 3 e $5 \%$, respectivamente.

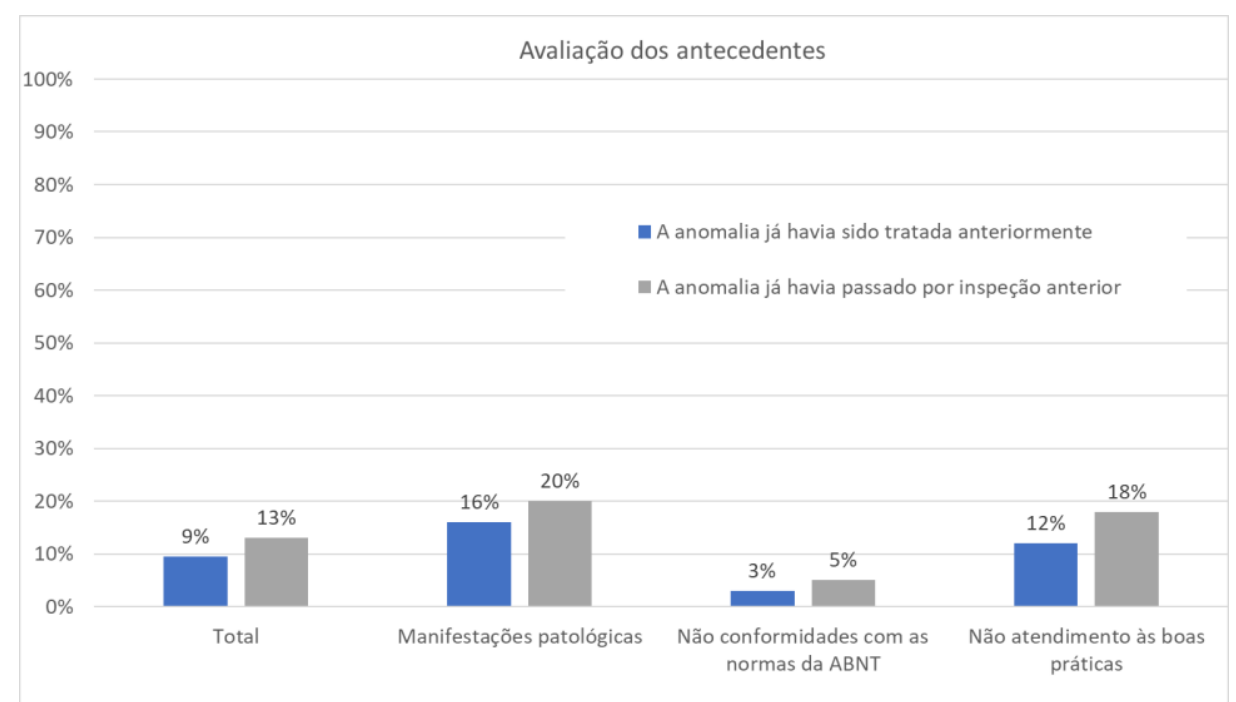

Figura 6: Avaliação dos antecedentes das anomalias estudadas neste trabalho

A maior frequência - das falhas em tratamentos e em inspeções técnicas realizadas anteriormente, observadas nas manifestações patológicas, e em seguida, nos não atendimentos às boas práticas, leva a crer que o fato de serem observadas a olho nu, mesmo por um leigo, levam o responsável a uma tomada de providência naquele tipo de anomalia: manifestação patógica ou não atendimento à boa prática. As não conformidades com as normas da ABNT, por sua vez, não são bem assimiladas pelos usuários e não lhes causam motivação para a tomada de providências.

\subsection{Adequação da percepção do usuário/responsável}

A percepção do usuário/responsável quanto ao progresso da anomalia e a sua "criticidade” está mostrada na Figura 7, onde pode-se observar que existe uma maior preocupação com as manifestações patológicas quando comparadas às demais anomalias - no que tange à observação do avanço na degradação do elemento, possivelmente pela mesma explicação do item anterior. O não atendimento às boas práticas, pelo visto, fica em segundo plano.

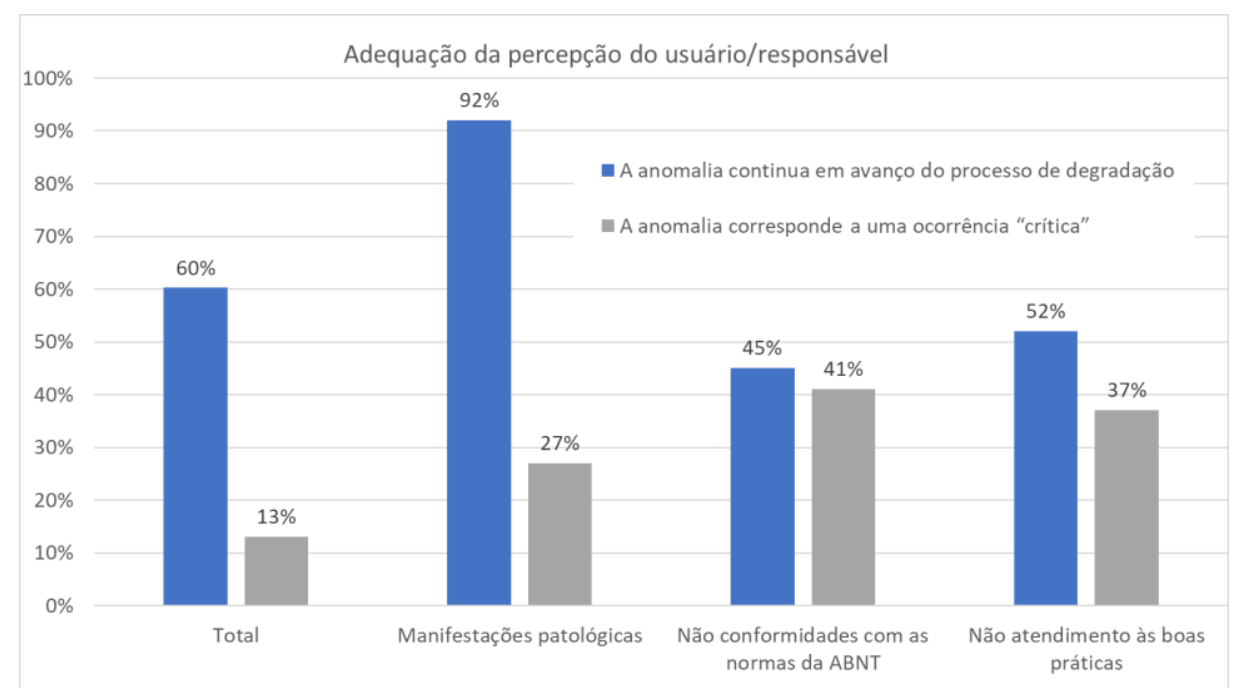

Figura 7: Adequação da percepção do usuário/responsável nas anomalias estudadas neste trabalho 


\subsection{Avaliação das causas principais das anomalias}

Na Figura 8 está apresentada a avaliação das causas principais das anomalias estudadas neste trabalho - e apresentadas na Tabela 2. Na figura pode-se observar que a causa Especificação/projeto é o item que mais se destaca em todos os modos de anomalia - em 32\%, 31\% e 38\%, com a excessão das manifestações patológicas, anomalias estas em que foram mais comuns os problemas de Execução de Instalações Hidrossanitárias (34\%), seguidos da causa de Especificação/projeto (27\%).

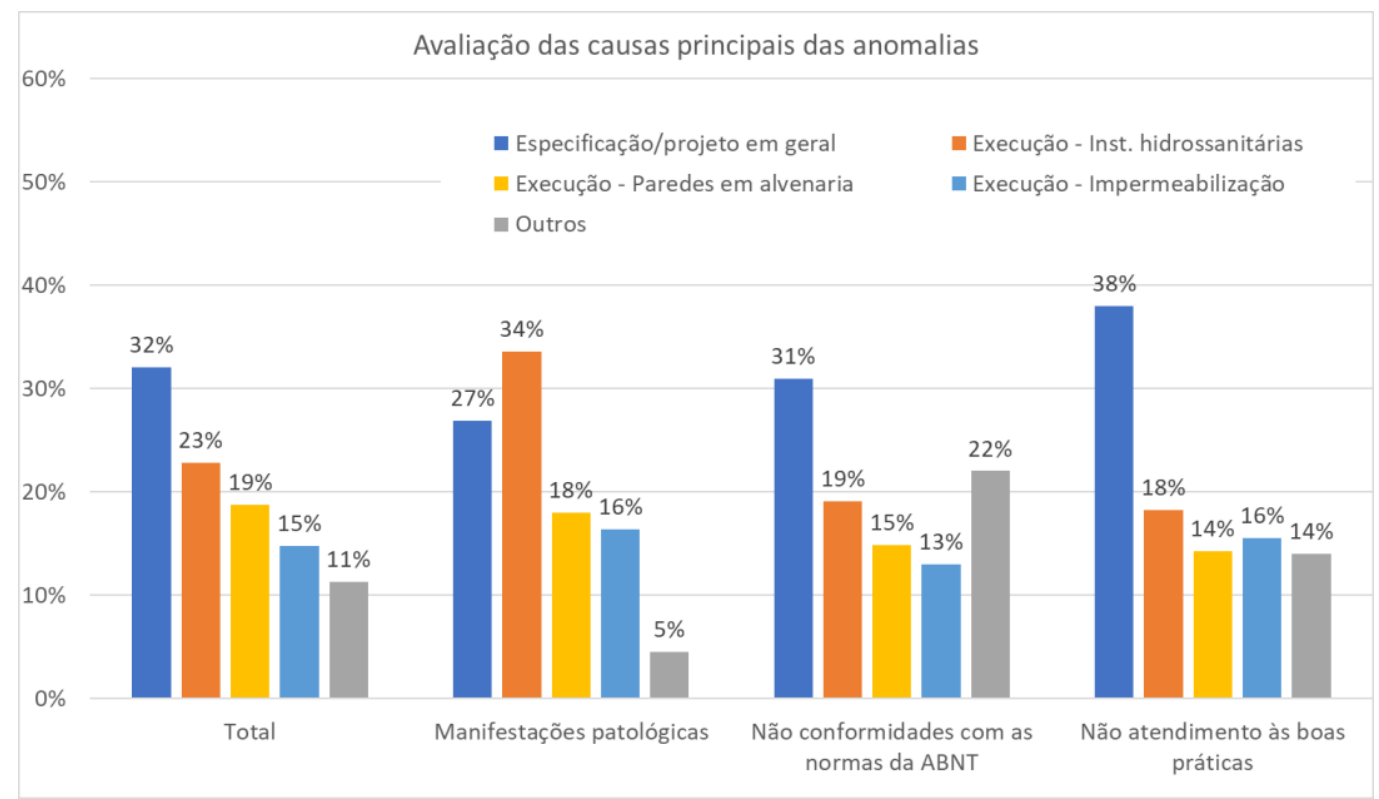

Figura 8: Avaliação das causas principais das anomalias estudadas neste trabalho

Pode-se observar, também na Figura 8, que a maior parte das anomalias fica distribuída entre os itens de Especificação/projeto, Execução de Instalações Hidrosanitárias, Execução de Paredes em Alvenaria, e Execução de Impermeabilização, que somam juntas cerca de $90 \%$ do total de anomalias (89\%, no gráfico). Em Outros, ficaram agrupadas outras causas das anomalias que não chegaram a representar $5 \%$ de frequência.

\section{CONCLUSÕES E CONSIDERAÇÕES FINAIS}

Este trabalho apresentou um estudo do histórico das patologias das construções apontadas em 17 laudos de Inspeção Predial realizados em condomínios de prédios residenciais (entre 6 e 16 pavimentos) na região metropolitana de Vitória/ES. As Inspeções Prediais, realizadas nos últimos 10 anos, avaliaram as manfestações patológicas, os não atendimentos às boas práticas de construção, e as não conformidades com as normas da ABNT, nas áreas comuns dos condomínios residenciais com idades entre 6 meses e 22 anos de entregues.

A avaliação das causas principais das anomalias, na Figura 8, mostrou que a maior parte das manifestações patológicas encontradas nas edificações estudadas, percentual de 95\%, se concentrou entre os itens de Projeto, de Especificação Técnica, e de Execução de Instalações Hidrossanitárias, de Paredes em Alvenaria, e de Impermeabilização. O item de Projeto/especificação, por sua vez, foi a principal causa das anomalias, com $32 \%$ da frequencia, representando cerca de $1 / 3$ de todas as anomalias estudadas.

Foi importante observar a correta adequação da percepção do usuário/responsável pelo imóvel com as criticidades das anomalias, concluindo que as manifestações patológicas despertam um maior senso de "criticidade" a eles, passando a impressão de continuidade no processo de degradação mais rápida que os demais tipos de anomalias - os não atendimentos às boas práticas de construção, e as não conformidades com as normas da ABNT, levando a uma mais rápida tomada de providências.

Também foi possível observar na avaliação dos antecedentes das anomalias estudadas neste trabalho que parte mais significativa das manifestações patológicas e dos não atendimentos às boas práticas de engenharia já havia sido observada por inspeção técnica anterior e supostamente tinham sido devidamente corrigida ou tratada, chegando a uma frequencia de $16 \%$, no caso das manifestações patológicas. 
A avaliação da manutenção dos elementos nos quais foram observadas as anomalias deste trabalho mostrou que entre 70 e $80 \%$ dos casos estudados a adequada manutenção não estava devidamente informada no Manual Proprietário. No entanto, um aspecto foi considerado positivo, pois nos mesmos casos, embora as informações não constassem nos Manuais, o percentual de desconhecimento dos procedimentos de manutenção ficou entre 40 e $60 \%$, abaixo daquele de existência da informação no Manual do Proprietário. Esta informação é importante, pois mostra que, embora não houvesse a informação no Manual do Proprietário, os usuários/proprietários tinham o conhecimento da manutenção adequada do elemento em que foi encontrada a anomalia, obtido por outros caminhos que não as especificações de uso da edificação.

Observou-se neste trabalho, ainda, que foi alto o percentual de casos de anomalias em elementos das edificações em que havia a informação correta do seu uso ou da sua operação no Manual do Proprietário, com 59\% de frequencia, e em ocasiões em que os usuários/proprietários tinham a ciência do seu uso ou da sua operação adequada, com $65 \%$ de frequencia.

Quanto a qualificação da frequência das anomalias do trabalho, observou-se em média, 32 manifestações patológicas, 47 não conformidades com as normas técnicas da ABNT, e 38 não atendimentos à boa prática de engenharia, num total de 117 apontamentos para cada edificação avaliada. Na ocasião, foi importante a constatação de que as edificações mais novas foram aquelas que apresentaram a maior quantidade de apontamentos por laudo técnico.

Também foi importante destacar que somente a adequação da construção aos requisitos de projeto/especificação não resolve o problema das patologias, pois observou-se que a maior parte das anomalias atendeu aos requisitos de projeto/especificação, com $65 \%$, chegando a $85 \%$ da frequencia para as não conformidades com as normas da ABNT. Esta informação mostra que os requisitos de projeto/especificação que chegam até a execução ainda são carentes de informação técnica e se destacam como ponto de melhoria no processo. Como já comentado, é importante ressaltar que as avaliações de não conformidade e de não atendimento às boas práticas deste trabalho levaram em consideração os requisitos atuais, e não aqueles praticados à época do projeto, o que quer dizer que não necessáriamente os elementos foram mal projetados, eles apenas estão fora dos requisitos atualmente adotados como boa técnica e boa prática. Este tipo de avaliação toma importância, à medida que em uma posterior sugestão de recuperação ou readequação da anomalia, deve-se prever, sempre que possível, o estabelecimento das condições atuais de requisitos e não o restabelecimento das condições de requisitos que foram estabelecidas no projeto de concepção original ou em eventuais intervenções de adequação já realizadas.

Por último, como já frisado, é importante observar que os dados deste trabalho se tratam de resultados de inspeções onde já se sabia de antemão que havia anomalias e falhas nas edificações, por solicitação expressa dos seus proprietários, não sendo neste sentido um estudo que contemple aleatoriedade e, logo, rigor nas indicações estatísticas dos resultados.

\section{AGRADECIMENTOS}

O Autor deixa aqui registrado o agradecimento aos representantes formais dos proprietários dos imóveis avaliados, que permitiram a utilização das informações contidas nos laudos de Inspeção Predial.

\section{REFERÊNCIAS}

CÁnOVAS, M.F. Patologia e Terapia do Concreto Armado. 2 $2^{\text {a }}$ Edição. Editora PINI. 522p. São Paulo, 1998.

HELENE, P.R.L. Manual para Reparo, Reforço e Proteção de Estruturas de Concreto. 2a Edição. Editora PINI. 213p. São Paulo, 1992.

IBAPE - INSTITUTO BRASILEIRO DE AVALIAÇÕES E PERÍCIAS DE ENGENHARIA. Inspeção Predial: Check-Up Predial: Guia da Boa Manutenção. $1^{\text {a }}$ Edição. Ed. Leud. 248p. São Paulo. 2005.

IBAPE - INSTITUTO BRASILEIRO DE AVALIAÇÕES E PERÍCIAS DE ENGENHARIA. Norma de Inspeção Predial. São Paulo, SP, 2009.

LICHTENSTEIN, N.B. Procedimento para Formulação do Diagnósticos de Falhas e Definição de Conduta Adequada à Recuperação de Edificações. Dissertação (Mestrado). Escola Politécnica da Universidade de São Paulo.191p. São Paulo, 1985.

VERÇOZA, E.J. Patologia das Edificações. 1ª Edição. Ed. Sagra. 173p. Porto Alegre. 1991. 